3. Antoniou GA, Giannoukas AD, Georgiadis GS, Antoniou SA, Simopoulos C, Prassopoulos P, et al. Increased prevalence of abdominal aortic aneurysm in patients undergoing inguinal hernia repair compared with patients without hernia receiving aneurysm screening. J Vasc Surg. 2011;53:1184-8.
4. Henriksen NA, Sorensen LT, Jorgensen LN, Lindholt JS. Lack of association between inguinal hernia and abdominal aortic aneurysm in a population-based male cohort. Br J Surg. 2013;100:1478-82.

5. HerniaSurge Group. International guidelines for hernia management. Hernia. 2018;22:1-165
See Article page 1668.

\section{Commentary: Does a bulge beget a bulge? Association of abdominal wall hernias and aortic aneurysms}

\author{
Douglas M. Farmer, MD, and Ravi K. Ghanta, MD
}

Aortic aneurysms have long been of clinical interest given the high mortality associated with rupture, which can be prevented with surgical repair. Abdominal wall hernias, a more common and benign entity, have been studied and compared with aneurysms in an attempt to find a shared pathophysiologic mechanism. Matrix metalloproteinase activity has been shown to be abnormal in patients with both hernias and aneurysms. ${ }^{1,2}$ Observational studies have been limited by small numbers. Larger studies have been done, but have not been inclusive of all abdominal hernia and aortic aneurysm patients. ${ }^{3}$ Given the low prevalence of aneurysms, routine screening via imaging is only indicated in patients with either known connective tissue disorders or with specific risk factors. ${ }^{4}$ Thus, identifying a common, benign diagnosis that may predict another less common and more lethal diagnosis could be of clinical significance for early detection and treatment.

Hung and colleagues ${ }^{5}$ report their findings of a retrospective, population-based cohort study to see if the presence of an abdominal wall hernia is associated with developing an aortic aneurysm. They used Taiwan's national health care database to identify all patients with nonincisional

\footnotetext{
From the Division of Cardiothoracic Surgery, Michael E. DeBakey Department of Surgery, Baylor College of Medicine, Houston, Tex.

Disclosure: Authors have nothing to disclose with regard to commercial support.

Received for publication Feb 20, 2020; accepted for publication Feb 21, 2020; available ahead of print March 12, 2020.

Address for reprints: Ravi K. Ghanta, MD, Division of Cardiothoracic Surgery, Michael E. DeBakey Department of Surgery, Baylor College of Medicine, One Baylor Plaza, MC 390, Houston, TX 77030 (E-mail: Ravi.ghanta@bcm.edu). J Thorac Cardiovasc Surg 2021;162:1679-80 $0022-5223 / \$ 36.00$

Copyright (c) 2020 by The American Association for Thoracic Surgery https://doi.org/10.1016/j.jtcvs.2020.02.106
}

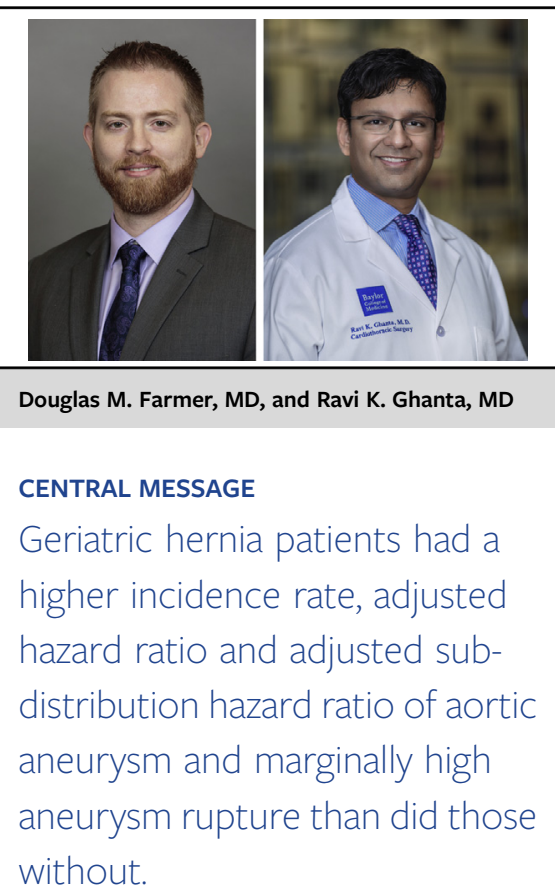

abdominal wall hernias who subsequently developed either a thoracic or abdominal aortic aneurysm within a 12-year period. Additionally, they compared rates of aneurysm rupture between hernia and nonhernia patients. Patients with known aneurysms at the time of hernia diagnosis, or those with known high-risk conditions for aneurysm formation, where excluded. In both unadjusted and risk-adjusted analysis, the incidence of aortic aneurysm was higher in those with a hernia than those without. This increase was significantly higher within the geriatric (age $\geq 65$ years) subgroup. Moreover, patients in the hernia group who developed an aneurysm had a higher risk for rupture. They found no difference in the total number of imaging studies between groups, suggesting no detection bias for aneurysms.

There are several limitations to this study. First, the authors only considered new diagnoses of both hernia and aneurysm, thus only capturing a portion of a potentially longer time interval for aneurysm development. This may 
have simply been a limitation of their database. Second, certain known risk factors for hernias and aneurysms (eg, smoking and family history) ${ }^{6,7}$ were not included but are relevant given the multifactorial nature of both diseases. Similarly, because aneurysm prevalence differs by both race and geography, these findings might not be generalizable for groups with a higher disease burden.

This study is unique because it describes a large population and included all abdominal hernias and aortic aneurysms. It provides real-world clinical data suggesting an association between hernias and aneurysms. However, the authors correctly conclude that this study is not sufficient to deduce either direct correlation or causation, nor does it provide a strong enough basis to change current screening guidelines. A similar study with diverse cohorts of age, gender, and race over a larger time period would be of potential interest.

\section{References}

1. Antoszewska M. Evaluation of the levels of metalloproteinsase-2 in patients with abdominal aneurysm and abdominal hernias. Pol Przegl Chir. 2013;85:271-8.

2. Antoniou GA, Georgiadis GS, Antoniou SA, Granderath FA, Giannoukas AD, Lazarides MK. Abdominal aortic aneurysm and abdominal wall hernia as manifestations of a connective tissue disorder. J Vasc Surg. 2011;54:1175-81.

3. Henriksen NA, Sorensen LT, Jorgensen LN, Lindholt JS. Lack of association between inguinal hernia and abdominal aortic aneurysm in a population-based male cohort. Br J Surg. 2013;100:1478-82.

4. Lederle FA, Johnson GR, Wilson SE, Chute EP, Littooy FN, Bandyk D, et al. Prevalence and associations of abdominal aortic aneurysm detected through screening. Aneurysm detection and management (ADAM) veterans affairs cooperative study group. Ann Intern Med. 1997;126:441-9.

5. Hung K-C, Chang Y-J, Sun C-K, Wang J-J, Chen Y-C, Weng S-F, et al. Association of hernia with subsequent aortic aneurysm in geriatric patients. J Thorac Cardiovasc Surg. 2021;162:1668-77.e2.

6. HerniaSurge Group. International guidelines for groin hernia management. Hernia. 2018;22:1-165.

7. Kent KC, Zwolak RM, Egorova NN, Riles TS, Manganaro A, Moskowitz AJ, et al Analysis of risk factors for abdominal aortic aneurysm in a cohort of more than 3 million individuals. J Vasc Surg. 2010;52:539-48.
See Article page 1668.

\section{Commentary: Everything matters}

\author{
Anthony L. Estrera, MD, FACS, and \\ Haider Al Rustem, BS
}

During 2005, the US Preventive Services Task Force (USPSTF) provided a recommendation that 1-time ultrasound abdominal aortic aneurysm (AAA) screening in men aged $>65$ years with a family history of AAA or a history of smoking ( $>100$ cigarettes in lifetime) was associated with reduced aortic rupture and related mortality. ${ }^{1}$

The Centers for Medicare and Medicaid Services (CMS) subsequently approved payment for this screening with an appropriate referral as part of an Initial Preventive Physical Examination. During 2014, the USPSTF performed an updated analysis regarding screening for AAA that further

\footnotetext{
From the Department of Cardiothoracic and Vascular Surgery, McGovern Medical School at The University of Texas Health Science Center at Houston and Memorial Hermann Hospital, Houston, Tex.

Disclosure: Dr Estrera is a consultant for WL Gore \& Associates.

Received for publication Feb 27, 2020; accepted for publication Feb 27, 2020; available ahead of print March 12, 2020.

Address for reprints: Anthony L. Estrera, MD, FACS, Department of Cardiothoracic and Vascular Surgery, McGovern Medical School at The University of Texas Health Science Center at Houston, 6400 Fannin St, Suite 2850, Houston, TX 77030 (E-mail: Anthony.L.Estrera@uth.tmc.edu).

J Thorac Cardiovasc Surg 2021;162:1680-3

$0022-5223 / \$ 36.00$

Copyright (c) 2020 by The American Association for Thoracic Surgery

https://doi.org/10.1016/j.jtcvs.2020.02.105
}

Check for updates

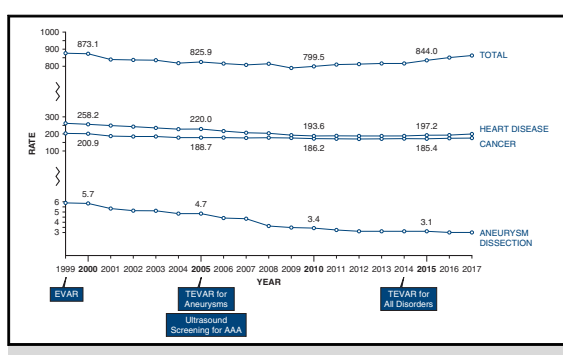

US mortality rate for total, heart disease, cancer, aneurysms, and dissection events per 100,000 population.

\section{CENTRAL MESSAGE \\ Hernias may be associated with \\ AAA but current guidelines for \\ ultrasound screening do not \\ include it as a risk factor. Further \\ work is required to improve un- \\ derstanding and decrease the \\ death rate from aneurysms and \\ dissection.}

corroborated the continued benefit of ultrasound screening, especially in late follow-up. This led CMS to lift the referral requirement on payment coverage of AAA ultrasound screening, such that any clinical provider could request the screening ultrasound. ${ }^{2}$ 